\title{
Mulheres idosas enfrentando a institucionalização
}

\author{
Elderly women dealing with institutionalization
}

\footnotetext{
${ }^{1}$ Universidade Regional Integrada do Alto Uruguai e das Missões, Erechim, Brasil. 2 Programa de Pós-graduação em Saúde Coletiva, Universidade do Vale do Rio dos Sinos, São Leopoldo, Brasil.

Correspondência S. N. Meneghel Programa de Pós-graduação em Saúde Coletiva Universidade do Vale do Rio dos Sinos. Av. Unisinos 950 , São Leopoldo, RS 93022-000, Brasil. meneghel@unisinos.br
}

\begin{abstract}
This study focused on institutionalization of the elderly from the perspective of gender studies. The aim was to understand the effects of institutionalization on the lives of elderly women and their strategies to deal with this situation. The study used a qualitative methodology and was conducted in a long-term care facility for the elderly, with 110 individuals from Alto Uruguai, Rio Grande do Sul State, Brazil. Data collection used discussion groups with ten elderly women participating. Content analysis was used and identified three main categories: the nursing home as a total institution, gender, and strategies to deal with institutionalization. Half of the women had chosen to live in the nursing home, while the others complained about their confinement to what they considered "a dump for old people". The gender category permeated the women's lives, which included domestic activities in the "home" in order to pass the time. Strategies to deal with institutionalization included religious rituals, handicrafts, and walks.
\end{abstract}

Health of Institutionalized Elderly; Aging;Women
Fábio José Pavan 1

Stela Nazareth Meneghel 2

José Roque Junges 2

\section{Introdução}

Dados demográficos apontam um aumento contínuo da proporção de pessoas idosas, trazendo novos e complexos problemas sociais e econômicos. Em 2025, o Brasil terá 32 milhões de pessoas com sessenta anos ou mais, tornando-nos a sexta maior população idosa do mundo.

A velhice está atravessada pelas questões de gênero ${ }^{1,2}$. As mulheres idosas experimentam uma probabilidade maior de ficarem viúvas, em situação sócio-econômica desvantajosa e com necessidades especiais ${ }^{3}$. Nos últimos anos tem ocorrido um acentuado aumento nas taxas de institucionalização de idosos, como conseqüência da maior participação feminina na força de trabalho. No Brasil, existem 200 mil abrigos para idosos, e a maior parte de asilados é do sexo feminino 4,5 .

Esta pesquisa partiu do desejo de saber como a mulher idosa percebe a institucionalização, quais os efeitos decorrentes de gênero e de que maneira estas idosas enfrentam o envelhecimento na situação de asilamento.

\section{Caminho metodológico}

Esta pesquisa utilizou abordagem qualitativa 6 . O campo de estudo é uma instituição de longa permanência, localizada em um município de médio porte da região norte do Rio Grande do 
Sul, Brasil, que atende cerca de 110 idosos, 80\% do sexo feminino. A coleta das informações ocorreu por meio de quatro grupos de discussão com a participação de dez idosas. No primeiro encontro, elas foram esclarecidas sobre os objetivos do estudo e assinaram o Termo de Consentimento Livre e Esclarecido. Este estudo faz parte de uma pesquisa denominada Histórias de Resistência de Mulheres, aprovada pelo Comitê de Ética em Pesquisa da Universidade do Vale do Rio dos Sinos.

Os temas tratados em cada um dos encontros foram: estórias de mulheres; a vida no asilo e enfrentando o cotidiano. A técnica utilizada para a análise das informações foi a análise de conteúdo temática 7 .

Identificamos três temas principais para nortear a discussão: o asilo como instituição total; os efeitos de gênero no envelhecimento; e os modos de enfrentamento do asilamento e da velhice.

\section{Resultados e discussão}

\section{Asilo como instituição total}

Uma das questões discutidas no grupo referiu-se ao processo de institucionalização. Metade das participantes do grupo afirmou que elas escolheram essa opção e que gostam de viver no asilo, enquanto que as outras foram abandonadas, enganadas com mentiras e/ou falsas promessas de retorno a casa ou ainda internadas à revelia.

O funcionamento do asilo como instituição total 8,9 aparece nos relatos das idosas que precisam adaptar-se e aceitar normas e regulamentos. A institucionalização acelera e/ou acentua a velocidade das perdas funcionais dos idosos, forçando o declínio das funções física e cognitiva, além da submissão ao governo do asilo 5 .

O poder disciplinar implementado nas instituições totais promove a distribuição dos indivíduos no espaço, utilizando procedimentos como o controle do tempo e o enclausuramento. As "regras da casa" especificam a austera rotina diária em um ambiente rígido, onde um pequeno número de prêmios ou privilégios pode ser alcançado em troca de obediência. As instituições totais fundamentam-se no controle e na hierarquia, o tratamento é uniformizado, a rotina é regida por horários preestabelecidos e os idosos perdem o direito de expressar sua subjetividade e seus desejos.

Várias idosas mostraram-se indignadas com os métodos utilizados para administrar a vida diária no ambiente asilar e afirmaram que a instituição é um “depósito de velhos", uma situação freqüentemente acompanhada pelo sentimento de humilhação, pois a posição de pouco ou ne- nhum prestígio social gera tristeza e pode diminuir o tempo de vida 10 .

As instituições asilares lembram grandes alojamentos, raramente articulam propostas para incentivar a independência e autonomia dos usuários. Eles vivem, na maioria das vezes, com possibilidades limitadas de vida social, afetiva e sexual. Confirma-se a situação de "depósitos" de pessoas, fundamentada na idéia do amparo aos desabrigados.

Ouvimos inúmeros depoimentos de institucionalização forçada, uma situação em que a internação em vez de se tornar uma alternativa negociada, configura um abuso de poder, que os deixa na situação de sobrantes, supérfluos e desempoderados.

\section{Efeitos de gênero no envelhecimento}

Utilizamos o conceito de gênero ${ }^{1}$ entendendo que o fato de ser mulher pode constituir uma condição a mais de vulnerabilidade para idosos institucionalizados. As mulheres que vivem na instituição apresentam baixo nível de escolaridade, a maioria delas tinha sido domésticas, donasde-casa, agricultoras e trabalhadoras braçais. Oriundas de cidades de pequeno porte e região rural, de origem italiana ou alemã, culturas em que ser homem e mulher estão moldados em rígidos padrões e estereótipos 11. Possuem poucos recursos financeiros; sozinhas, por não terem casado ou por estarem viúvas, para elas a única opção foi o asilamento. Além do mais, elas perderam os espaços de sociabilidade característicos das pequenas comunidades rurais, onde a identidade familiar e as redes comunitárias constituem laços poderosos.

Sofrem os efeitos da violência simbólica, de terem sido destituídas de suas casas e pertences, das relações familiares, de amizade e vizinhança, de suas próprias histórias e vidas. A aceitação do papel e do destino feminino apareceu nos depoimentos em que o asilo é tratado como um "lar", uma designação eufemística de muitas casas/ abrigo. No asilo muitas das atividades domésticas e/ou do cotidiano/universo feminino são obrigatórias, embora invisibilizadas e sem valor de troca, conforme a tradicional divisão sexual do trabalho 12 em que a maior parte das atividades não remuneradas, repetitivas, tediosas e pouco valorizadas recai sobre as mulheres.

No discurso das mulheres, várias se referiram à comunidade asilar como uma "família" pautada na "lei e na disciplina", uma reprodução do discurso institucional em que os asilados permanecem numa situação de infantilização, destituídos da própria voz, repetindo aquilo que se espera deles 13 . 
Durante o processo grupal, entendemos que algumas das mulheres sentem o asilamento como uma situação de sofrimento, porém, na medida em que não têm alternativas, passam a aceitar esta condição. Outras, no entanto, não deixam de expressar, quer seja pelas lamentações, pela depressão ou pela tristeza, que não se resignaram à dependência e ausência de controle sobre suas vidas.

\section{Estratégias de enfrentamento à institucionalização}

Um dos objetivos deste estudo era o de saber como as idosas enfrentam a institucionalização e se a religiosidade era uma destas estratégias 14,15, já que a espiritualidade é uma ferramenta poderosa que ajuda a suportar a velhice, a doença e a morte.

No asilo, a religiosidade está presente no diaa-dia das mulheres, porém, nos pareceu que elas usam a fé mais como consolo do que como estratégia de resistência. Identificamos o tempo como um elemento que age sobre o idoso institucionalizado, acionando pensamentos repetitivos, tediosos, irrevogáveis. O tão sonhado tempo livre, no asilo se torna tempo vazio, tempo de espera da morte.

O "exercício" é a técnica por excelência pela qual se impõe aos corpos tarefas ao mesmo tempo repetitivas, diferentes e graduadas 9 . O idoso capaz de produzir ou trabalhar sai do aprisionamento da natureza socialmente (im)posta para poder usar, ou pelo menos representar, o corpo de maneira mais natural e menos fragmentada 16. Para algumas idosas o fato de poder sentir-se útil e produtiva torna a institucionalização menos dolorosa. Outras não se deixam capturar pelo entretenimento, o artesanato, bordar almofada, simplesmente recusam-se: "Eu não faço nada (...) não gosto...”.

Embora muitas idosas institucionalizadas tentem construir estratégias e meios para enfrentar a velhice e o asilamento, o tempo livre é em grande parte consumido na forma de lazer passivo, principalmente assistir à televisão. Outras ainda saem, têm livre acesso à instituição, cujo diferencial está em permitir aos que possuem condições físicas adequadas a liberdade de saírem quando desejam. Esse fato rompe com a rotina asilar de instituição total, pautada na tutela dos indivíduos, e permite algum controle do tempo, das atividades de vida diária, propiciando prazer e autonomia.

Entendemos que a institucionalização é um processo irreversível, em que parte da população idosa precisará necessariamente se submeter nas próximas décadas. As próprias transformações das relações sociais de gênero, eximindo as mulheres do ônus do cuidado obrigatório dos idosos, contribuem para essas mudanças. Porém, entendemos também que a institucionalização pode ser humanizada e funcionar em moldes mais abertos, para que as instituições de longa permanência de cuidado aos idosos não signifiquem apenas "depósitos de velhos". 


\section{Resumo}

O tema desta pesquisa é a institucionalização de idosos sob a perspectiva dos estudos de gênero. O objetivo é entender os efeitos do processo de institucionalização na vida de idosas e estratégias para enfrentar esta situação. A metodologia é qualitativa e a pesquisa foi realizada em uma instituição de longa permanência para idosos, que atende 110 pessoas procedentes da região do Alto Uruguai, Rio Grande do Sul, Brasil. Para a coleta dos dados foram organizados grupos de discussão com a participação de dez idosas. Utilizou-se a análise de conteúdo e foram identificadas três categorias principais: o asilo como instituição total, gênero, e estratégias de enfrentamento à institucionalização. Metade das mulheres escolheu viver no asilo, enquanto que outras denunciaram a situação de internação $e$ consideram o asilo "um depósito de velhos". A categoria gênero atravessa o fazer das mulheres que realizam atividades domésticas no "lar", para ajudar a passar o tempo. As estratégias para enfrentar o asilamento compreendem os rituais religiosos, as atividades artesanais e passeios.

Saúde do Idoso Institucionalizado; Envelhecimento; Mulheres

\section{Referências}

1. Saffiotti H. Gênero e patriarcado. In: Castillo-Martin M, organizadora. Marcadas a ferro. Brasília: Secretaria Especial de Políticas para as Mulheres; 2005. p. 35-76.

2. Alves PC. Nervoso e experiência de fragilização: narrativa de mulheres idosas. In: Minayo MCS, Coimbra Jr. CEA, organizadores. Antropologia, saúde e envelhecimento. Rio de Janeiro: Editora Fiocruz; 2002. p. 153-74.

3. Goldani AM. Mulheres e envelhecimento: desafios para os novos contratos intergeracionais e de gêneros. In: Camarano AA, organizador. Muito além dos 60: os novos idosos brasileiros. Rio de Janeiro: Instituto de Pesquisa Econômica Aplicada; 1999. p. 75-114.

4. Chamowicz F, Greco DB. Dinâmica da institucionalização de idosos em Belo Horizonte, Brasil. Rev Saúde Pública 1999; 33:454-60.

5. Montenegro SMR, Silva CAB. Os efeitos de um programa de fisioterapia como promotor de saúde na capacidade funcional de mulheres idosas institucionalizadas [Dissertação de Mestrado]. Fortaleza: Fundação Edson Queiroz; 2007.

6. Minayo MC. O desafio do conhecimento: pesquisa qualitativa em saúde. São Paulo: Editora Hucitec/ Rio de Janeiro: ABRASCO; 2006

7. Bardin L. Análise de conteúdo. Lisboa: Edições 70; 1979

8. Goffman E. Manicômios, prisões e conventos. São Paulo: Editora Perspectiva; 1990.

\section{Colaboradores}

F. J. Pavan, S. N. Meneghel e J. R. Junges elaboraram o artigo.

9. Foucault M. Vigiar e punir: nascimento da prisão Petrópolis: Editora Vozes; 1999.

10. Peixoto CE. Entre o estigma e a compaixão e os termos classificatórios: velho, velhote, idoso e terceira idade. In: Lins de Barros $\mathrm{M}$, organizador. Velhice ou terceira idade? Rio de Janeiro: Editora FGV; 1998. p. 69-84.

11. Heck RM, Langdon EJM. Envelhecimento, relações de gênero e papel das mulheres na organização da vida em uma comunidade rural. In: Minayo MCS, Coimbra Jr. CEA, organizadores. Antropologia, saúde e envelhecimento. Rio de Janeiro: Editora Fiocruz; 2002. p. 129-52.

12. Camarano AA. Mulher idosa: suporte familiar ou agente de mudança? Estud Av 2003; 17:35-63.

13. Vieira EB. Instituições geriátricas: avanço ou retrocesso? Rio de Janeiro: Editora Revinter; 2003.

14. Valla VV. Classes populares, apoio social e emoção: propondo um debate sobre religião e saúde no Brasil. In: Minayo MC, Coimbra Jr. CEA, organizadores. Críticas e atuantes: ciências sociais e humanas em saúde na América Latina. Rio de Janeiro: Editora Fiocruz; 2005. p. 77-89.

15. Vasconcelos EM. A Espiritualidade no trabalho em saúde. São Paulo: Editora Hucitec; 2006.

16. Minayo MCS, Coimbra Jr. CEA, organizadores. Antropologia, saúde e envelhecimento. Rio de Janeiro: Editora Fiocruz; 2002.

Recebido em 11/Jan/2008

Versão final reapresentada em 21/Jul/2008

Aprovado em 05/Ago/2008 